\title{
HPTLC analysis of Fumaria parviflora (Lam.) methanolic extract of whole plant
}

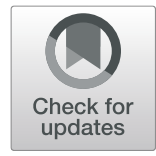

\author{
Anjali Bhargava ${ }^{1 *}$, Pragya Shrivastava ${ }^{1}$ and Anita Tilwari ${ }^{2}$
}

\begin{abstract}
Background: Fumaria parviflora (Lam.), commonly known as "fine-leaved fumitory," is well known for its therapeutic properties in the Indian traditional medicinal system. The presence of important bioactive compounds in plants makes them pharmacologically valuable. Therefore, in the present study, the high-performance thin layer chromatography (HPTLC) analysis of Fumaria parviflora (whole plant) methanolic extract was performed for its phytochemical profiling.

Results: The HPTLC densitometric analysis of the methanolic extract of Fumaria parviflora (whole plant) was carried out using CAMAG HPTLC system, and the results were obtained in the form of chromatograms (scanned at the wavelength of $254 \mathrm{~nm}$ and $366 \mathrm{~nm}$ ) representing several peaks. The phytochemical profile of the plant was determined and presented in the tables showing the total number of peaks, peak heights, peak area, percent area, and Rf values.
\end{abstract}

Conclusion: The study concluded that F. parviflora methanolic extract of the whole plant contains a rich variety of phytochemicals which might be accountable for its therapeutic value and thus justifies its traditional use in India.

Keywords: Fumaria parviflora, HPTLC, Methanolic extract, Densitometry, Chromatogram

\section{Background}

Medicinal plants, due to the presence of bioactive phytochemicals, play a very important role in human life for maintaining good health. The use of medicinal herbs in the treatment of infection is an age-old practice, and several natural products are used as phytotherapic for the treatment of many diseases [1]. The search for a newer source of antibiotics is a global challenge, since many infectious agents are becoming resistant to synthetic drugs [2]. There are thousands of medicinal plants known to have a long history of usage for their curative properties against various diseases and ailments [3]. The use of herbal drugs is once more escalating in the form of Complementary and Alternative Medicine (CAM) [4].

\footnotetext{
*Correspondence: bhargavaanjali17@gmail.com

'Department of Life Science, Rabindranath Tagore University,

Village-Mendua, Post-Bhojpur, Distt. Raisen, Bhopal, Madhya Pradesh 464993, India

Full list of author information is available at the end of the article
}

Fumaria parviflora Lam., commonly known as fineleaved fumitory (in English), Shahatra, Pittapapara, or Pittapapada (in Hindi), belongs to the family Fumariaceae. Fumaria parviflora (Fumariaceae) is a pale green, diffuse, much branched annual herb widely used in Ayurvedic medicine as well as in traditional Yunani system of medicine throughout India [5]. The entire herb is traditionally used in leprosy, fever [6], and detoxification and as laxative, diuretic, and diaphoretic [7].

The World Health Organization (WHO) has stressed on the need for scientific validity of herbal drugs and ensuring, devising, and implementing sound science [8]. Several techniques are available for the qualitative and quantitative estimation of phytochemicals present in plants. Nowadays, new technology has made it possible to identify, screen, and isolate these active compounds [9]. The HPTLC (high-performance thin layer chromatography) is an advanced form of TLC as it provides high resolution and much accurate data. It is accepted all over the world as one of the most 
powerful analytical techniques used for phytochemical and biomedical analysis. It is an inexpensive, simple, and rapid method for the estimation of chemical components present in test sample and therefore most widely used by pharmaceutical industries for new drug discovery. The present study was performed for the phytochemical profiling of Fumaria parviflora (whole plant) methanolic extract by the HPTLC technique.

\section{Method}

\section{Extraction}

The plant material was washed and then kept for shade drying for 7 days. The dried plant sample was powdered by mechanical grinder into a fine powder. The air-dried powdered material of the whole plant of Fumaria parviflora $(100 \mathrm{~g})$ was extracted with hydroalcoholic solvent [methanol and water solvent $(1: 1 \mathrm{v} / \mathrm{v})]$ using the Soxhletion process with the help of a Soxhlet apparatus. Excess solvent was then evaporated in a water bath at 50$100{ }^{\circ} \mathrm{C}$ to obtain the crude and stored in airtight containers.

\section{Instrumentation}

A CAMAG HPTLC system equipped with LINOMAT 5 applicator fitted with $100 \mu \mathrm{l}$ syringe, CAMAG TLC scanner, and winCATS software was used.

\section{Chemicals and solvents}

All the solvents used were of chromatography grade, and all the chemicals used were of analytical reagent grade.

\section{Preparation of samples}

Dried extract $(10 \mathrm{~g})$ of $F$. parviflora was dissolved in 100 $\mathrm{ml}$ HPTLC grade methanol and filtered. This solution was used as a test solution for the HPTLC study.

\section{Chromatographic conditions}

The HPTLC was performed on $7.0 \times 10.0 \mathrm{~cm}$ precoated silica gel $60 \mathrm{~F} 254$ HPTLC plate (E. MERCK KGaA). No pre-washing and modification of the plate were done. The sample solution was applied as bands to the plate by CAMAG Linomat applicator fitted with $100 \mu \mathrm{l}$ syringe (Table 1 ). The stable application rate was $150 \mathrm{nl} / \mathrm{s}$. The sample loaded plate was kept in automatic development chamber with mobile

Table 1 Tracks representing sample position and volume

\begin{tabular}{llllll}
\hline Track no. & Appl. position & Appl. volume & Vial \# & Sample ID & Active \\
\hline 1 & $15.0 \mathrm{~mm}$ & $4.0 \mu \mathrm{l}$ & 1 & $\mathrm{Fl01}$ & Yes \\
2 & $35.0 \mathrm{~mm}$ & $8.0 \mu \mathrm{l}$ & 1 & $\mathrm{Fl01}$ & Yes \\
\hline
\end{tabular}

Table 2 Parameters used for HPTLC

\begin{tabular}{|c|c|}
\hline Parameters & Values \\
\hline \multicolumn{2}{|l|}{ Calibration parameters } \\
\hline Calibration mode & Single level \\
\hline Statistics mode & CV \\
\hline Evaluation mode & Peak height \\
\hline \multicolumn{2}{|c|}{ Linomat 5 application parameters } \\
\hline Spray gas & Inert gas \\
\hline Sample solvent type & Methanol \\
\hline Dosage speed & $150 \mathrm{nl} / \mathrm{s}$ \\
\hline Predosage volume & $0.2 \mu \mathrm{l}$ \\
\hline Syringe size & $100 \mu l$ \\
\hline Application position & $8.0 \mathrm{~mm}$ \\
\hline Band length & $8.0 \mathrm{~mm}$ \\
\hline Solvent front position & $75.0 \mathrm{~mm}$ \\
\hline \multicolumn{2}{|c|}{ Detection-CAMAG TLC scanner } \\
\hline Number of tracks & 2 \\
\hline Position of track $X$ & $15.0 \mathrm{~mm}$ \\
\hline Distance between tracks & $20.0 \mathrm{~mm}$ \\
\hline Scan start position $Y$ & $5.0 \mathrm{~mm}$ \\
\hline Scan end position $Y$ & $75.0 \mathrm{~mm}$ \\
\hline Slit dimensions & $6.00 \times 0.30 \mathrm{~mm}$, micro \\
\hline Optimize optical system & Light \\
\hline Scanning speed & $20 \mathrm{~mm} / \mathrm{s}$ \\
\hline Data resolution & $100 \mu \mathrm{m} / \mathrm{step}$ \\
\hline \multicolumn{2}{|l|}{ Integration: properties } \\
\hline Data filtering & Savitsky-Golay 7 \\
\hline Baseline correction & Lowest slope \\
\hline Peak threshold min. slope & 5 \\
\hline Peak threshold min. height & $10 \mathrm{AU}$ \\
\hline Peak threshold min. area & 50 \\
\hline Peak threshold max. height & $990 \mathrm{AU}$ \\
\hline Track start position & $5.0 \mathrm{~mm}$ \\
\hline Track end position & $75.0 \mathrm{~mm}$ \\
\hline Display scaling & Automatic \\
\hline \multicolumn{2}{|l|}{ Measurement } \\
\hline Wavelength & $254 \mathrm{~nm}$ and $366 \mathrm{~nm}$ \\
\hline Lamp & $\mathrm{D} 2 / \mathrm{Hg}$ \\
\hline Measurement type & Remission \\
\hline Measurement mode & Absorption/fluorescence \\
\hline Optical filter & Second order/K400 \\
\hline Detector mode & Automatic \\
\hline PM high voltage & $181 \mathrm{~V}$ \\
\hline
\end{tabular}


phase-chloroform:ethyl acetate:formic acid (5:4:1 v/v/ v). Densitometric scanning was performed with CAMAG TLC scanner-4 equipped with winCATS software. The bands were visualized using CAMAG visualizer, and the images were captured in white light and $254 \mathrm{~nm}$ (short UV) and $366 \mathrm{~nm}$ (long UV) wavelengths (Table 2). When exposed to short-wave UV light of $254 \mathrm{~nm}$, UV-active compounds will undergo fluorescence quenching and appear as dark spots on a bright background. Conversely, compounds that absorb $366 \mathrm{~nm}$ UV light will appear as bright spots on a dark background [10].

\section{Results}

The HPTLC analysis of F. parviflora Lam. revealed the presence of various phytochemicals as illustrated in the figures and tables below. The chromatograms (Figs. 1, 2, 3, and 4) were obtained upon scanning at UV $254 \mathrm{~nm}$ and $366 \mathrm{~nm}$, and peak tables were generated. The Rf values, peak height, peak area, and percent area of the unknown substances are depicted in the tables (Tables 3, 4, 5, and 6).

\section{Discussion}

The HPTLC performed on the methanolic extract of Fumaria parviflora (Lam.) showed the presence of various phytoconstituents in different concentrations as illustrated in figures and tables. Figure 1 represents the 3-dimensional overlay of the chromatogram of all tracks, at all measured wavelengths. The chromatogram scanned at $254 \mathrm{~nm}$ (Fig. 2) represents 11 and 10 peaks for track 1 and track 2, respectively, whereas the chromatogram scanned at $366 \mathrm{~nm}$ (Fig. 3) indicates 9 and 12 peaks for track 1 and track 2, respectively. The number of peaks indicates the presence of different phytoconstituents present in the sample. The Rf values (Tables 3, 4, 5, and 6) calculated for the phytoconstituents present in the tested sample would be helpful in the identification of the unknown compounds by comparing them with the reference standards, and from the values of peak area, the

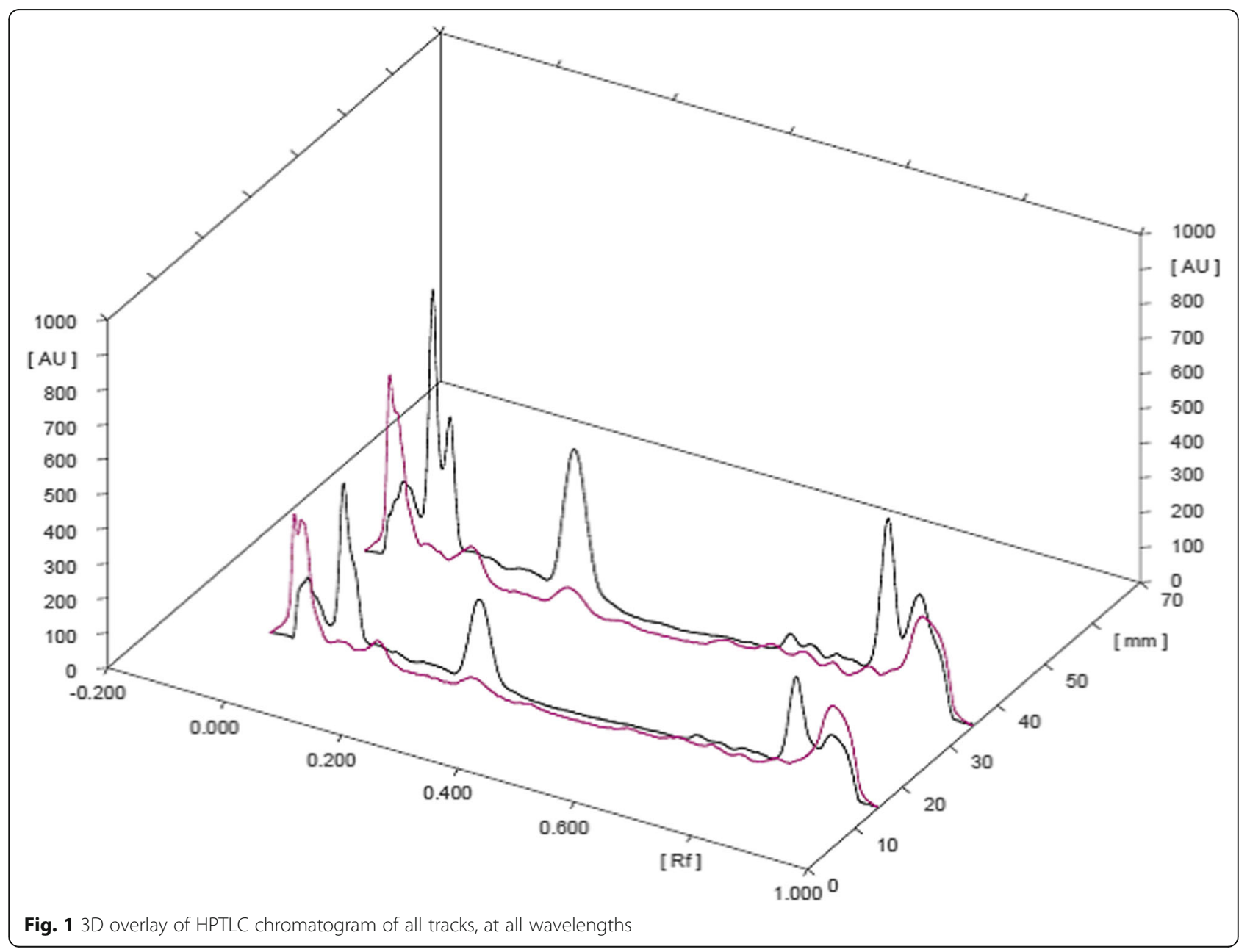




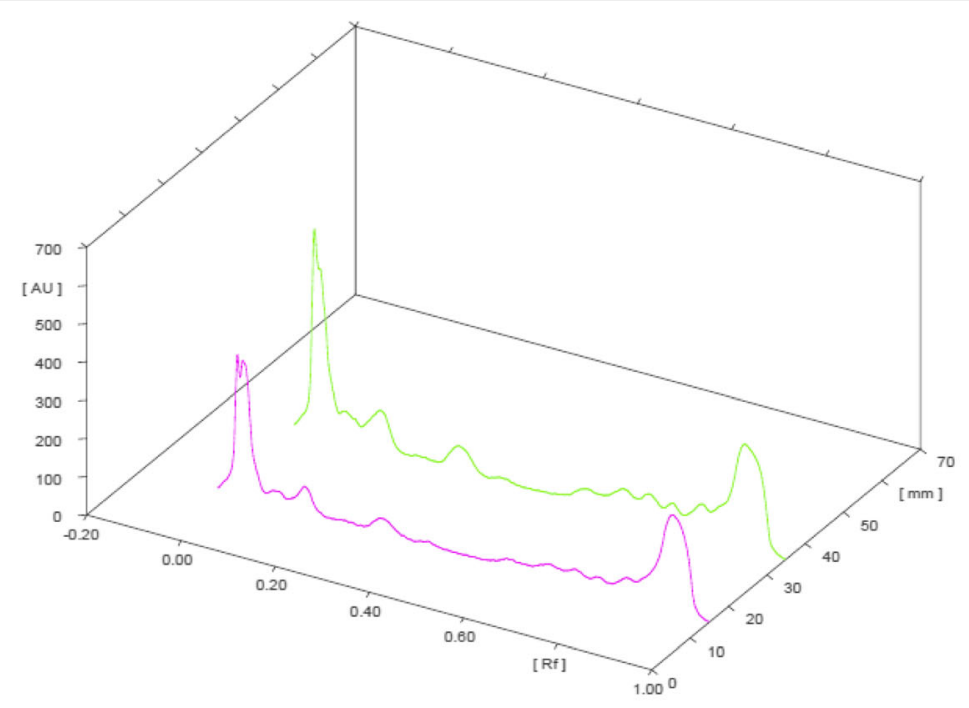

| Track 1, ID: Fl01
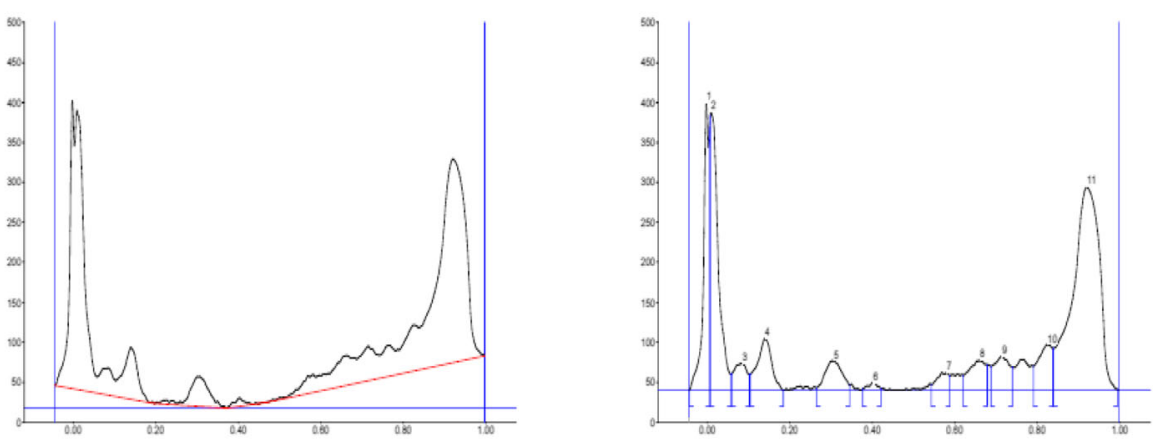

| Track 2, ID: F101
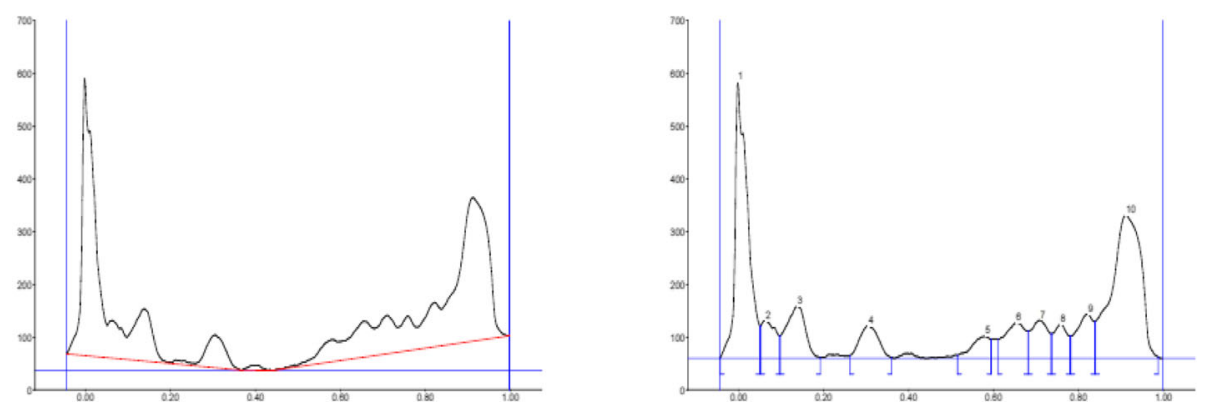

Fig. 2 HPTLC chromatograms scanned at $254 \mathrm{~nm}$ 


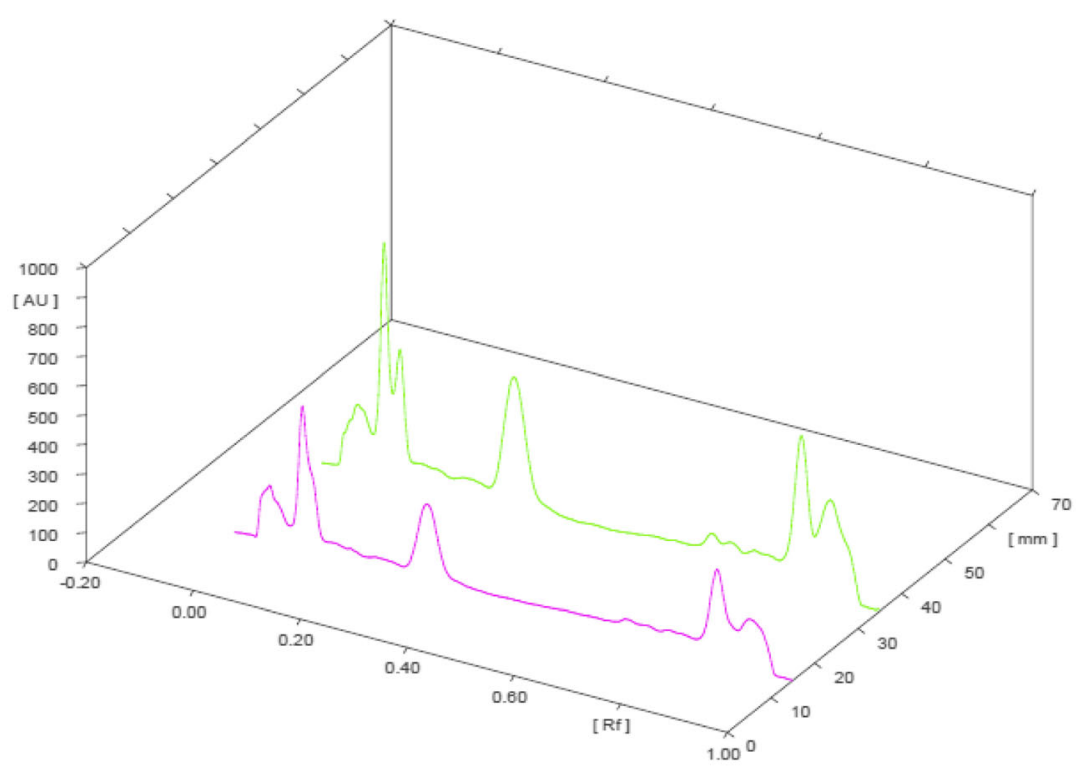

| Track 1, ID: F101
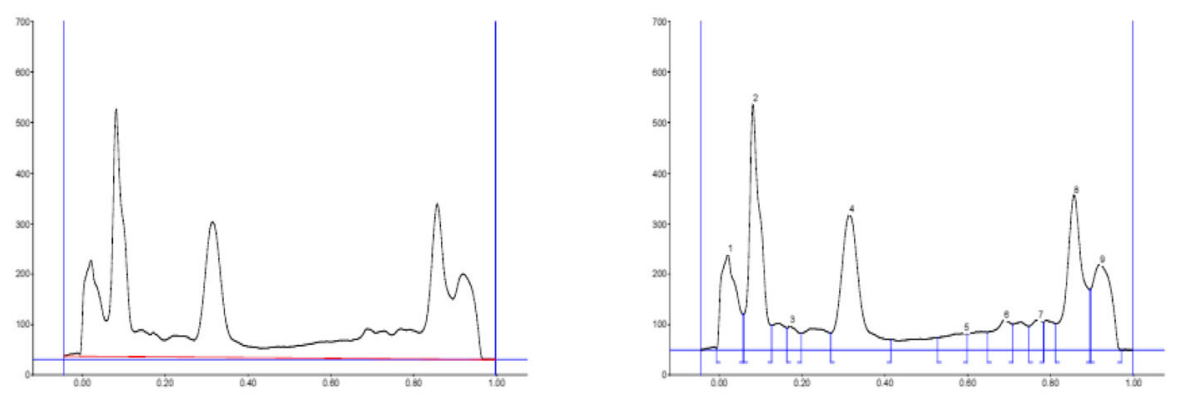

| Track 2, ID: Fl01
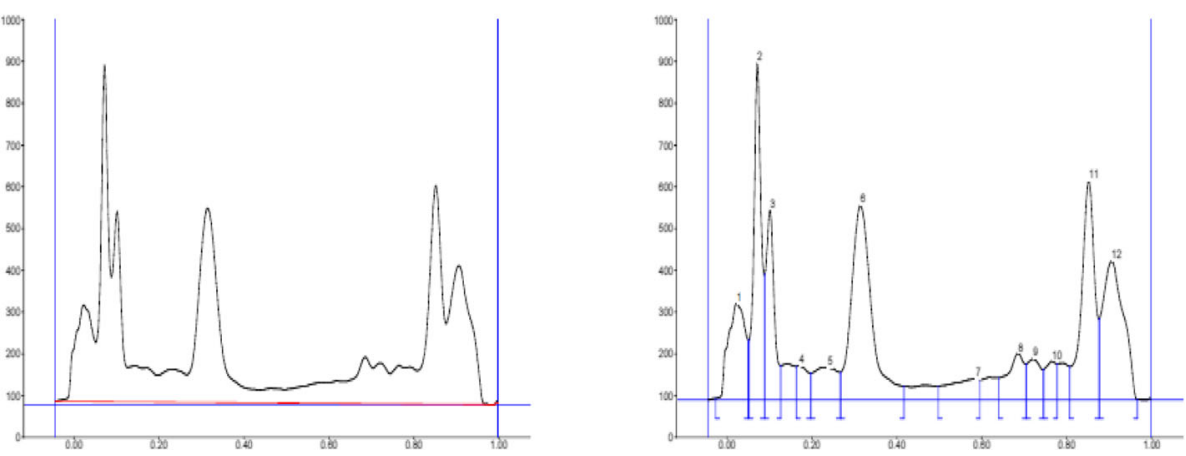

Fig. 3 HPTLC chromatograms scanned at $366 \mathrm{~nm}$ 


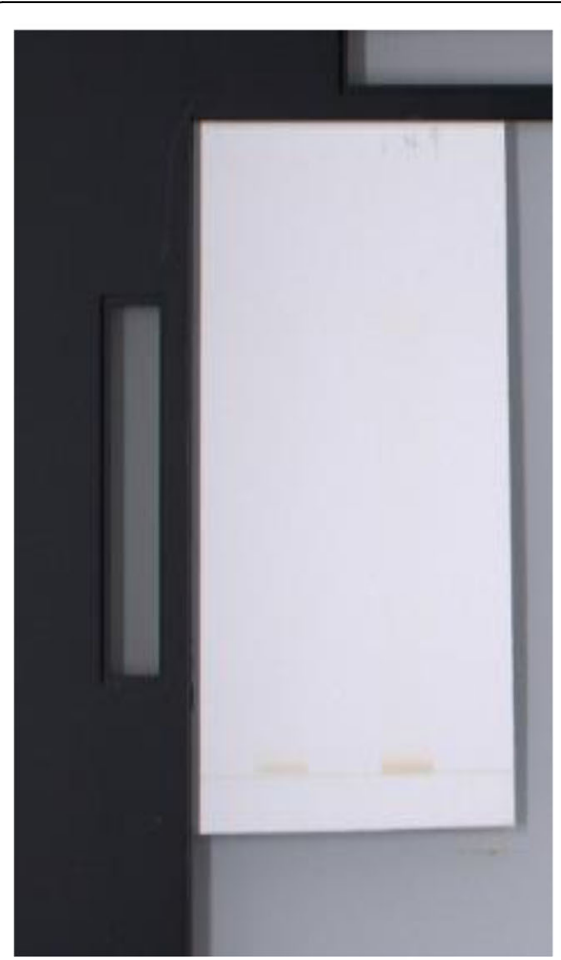

(a)

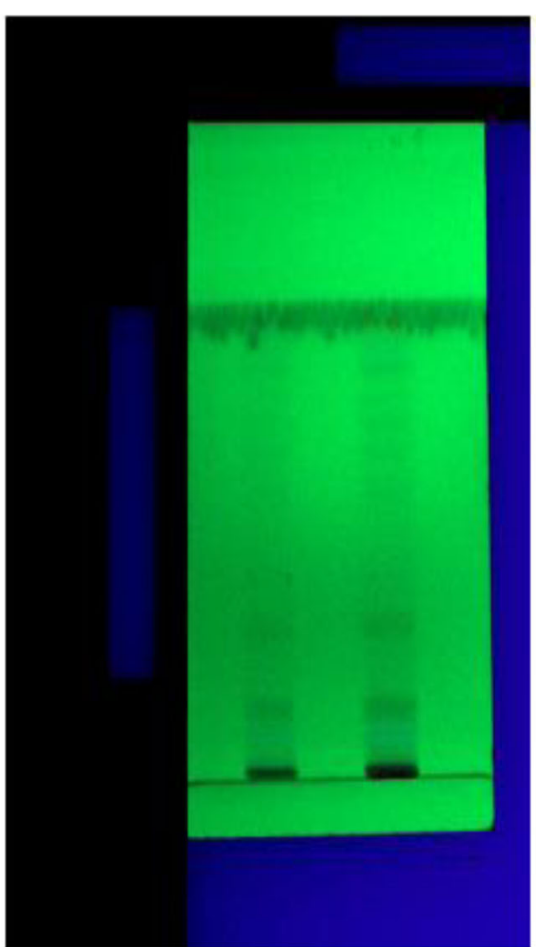

(b)

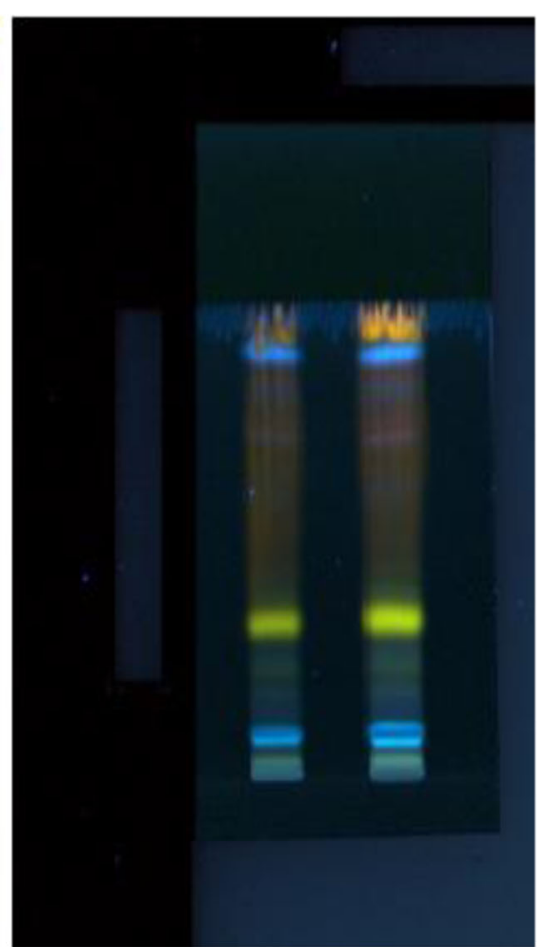

(c)

Fig. 4 HPTLC chromatograms visualized under a white light, b UV $254 \mathrm{~nm}$, and c UV $366 \mathrm{~nm}$

Table 3 HPTLC peak table of methanolic extract of F. parviflora Lam. (at $254 \mathrm{~nm}$, track 1)

\begin{tabular}{ccccccccccc}
\hline Peak & $\begin{array}{c}\text { Start } \\
\text { Rf }\end{array}$ & $\begin{array}{c}\text { Start } \\
\text { Height }\end{array}$ & $\begin{array}{c}\text { Max } \\
\text { Rf }\end{array}$ & $\begin{array}{c}\text { Max } \\
\text { Height }\end{array}$ & $\begin{array}{c}\text { Max } \% \\
\text { \% }\end{array}$ & $\begin{array}{c}\text { End } \\
\text { Rf }\end{array}$ & $\begin{array}{c}\text { End } \\
\text { Height }\end{array}$ & \multicolumn{1}{c}{ Area } & $\begin{array}{c}\text { Area } \\
\%\end{array}$ & Assigned substance \\
\hline 1 & -0.04 & 0.3 & -0.00 & 360.5 & 28.35 & 0.01 & 328.5 & 3987.7 & 12.95 & unknown * \\
2 & 0.01 & 343.7 & 0.01 & 349.3 & 27.47 & 0.06 & 20.8 & 5327.5 & 17.30 & unknown * \\
3 & 0.06 & 21.1 & 0.09 & 33.9 & 2.67 & 0.10 & 20.5 & 848.8 & 2.76 & unknown * \\
4 & 0.10 & 20.7 & 0.14 & 64.9 & 5.11 & 0.19 & 0.2 & 1761.9 & 5.72 & unknown * \\
5 & 0.27 & 3.2 & 0.31 & 37.3 & 2.93 & 0.35 & 6.3 & 1208.9 & 3.92 & unknown * \\
6 & 0.38 & 1.8 & 0.40 & 10.4 & 0.81 & 0.42 & 2.6 & 185.9 & 0.60 & unknown * \\
7 & 0.54 & 7.6 & 0.58 & 22.5 & 1.77 & 0.59 & 18.8 & 527.0 & 1.71 & unknown * \\
8 & 0.62 & 19.2 & 0.66 & 37.6 & 2.95 & 0.68 & 32.3 & 1227.2 & 3.98 & unknown * \\
9 & 0.69 & 30.3 & 0.72 & 43.2 & 3.39 & 0.74 & 29.4 & 1291.5 & 4.19 & unknown * \\
10 & 0.79 & 30.3 & 0.83 & 57.5 & 4.52 & 0.84 & 52.8 & 1553.6 & 5.04 & unknown * \\
11 & 0.84 & 53.0 & 0.92 & 254.7 & 20.03 & 1.00 & 1.5 & 12880.6 & 41.82 & unknown * \\
\hline
\end{tabular}


Table 4 HPTLC peak table of methanolic extract of F. parviflora Lam. (at $254 \mathrm{~nm}$, track 2)

\begin{tabular}{ccccccccccc}
\hline Peak & $\begin{array}{c}\text { Start } \\
\text { Rf }\end{array}$ & $\begin{array}{c}\text { Start } \\
\text { Height }\end{array}$ & $\begin{array}{c}\text { Max } \\
\text { Rf }\end{array}$ & $\begin{array}{c}\text { Max } \\
\text { Height }\end{array}$ & $\begin{array}{c}\text { Max } \% \\
\%\end{array}$ & $\begin{array}{c}\text { End } \\
\text { Rf }\end{array}$ & $\begin{array}{c}\text { End } \\
\text { Height }\end{array}$ & \multicolumn{1}{c}{ Area } & $\begin{array}{c}\text { Area } \\
\%\end{array}$ & Assigned substance \\
\hline 1 & -0.04 & 2.4 & -0.00 & 525.4 & 38.55 & 0.05 & 61.7 & 12155.7 & 27.16 & unknown * \\
2 & 0.05 & 62.1 & 0.06 & 71.5 & 5.25 & 0.10 & 42.4 & 1887.1 & 4.22 & unknown * \\
3 & 0.10 & 42.7 & 0.14 & 99.1 & 7.27 & 0.19 & 1.5 & 3453.6 & 7.72 & unknown * \\
4 & 0.26 & 6.0 & 0.31 & 62.6 & 4.59 & 0.36 & 1.7 & 2182.4 & 4.88 & unknown * \\
5 & 0.52 & 6.4 & 0.58 & 41.9 & 3.07 & 0.60 & 36.1 & 1419.3 & 3.17 & unknown * \\
6 & 0.61 & 36.4 & 0.66 & 68.2 & 5.00 & 0.68 & 51.9 & 2608.7 & 5.83 & unknown * \\
7 & 0.68 & 52.2 & 0.71 & 72.7 & 5.34 & 0.74 & 47.3 & 2259.6 & 5.05 & unknown * \\
8 & 0.74 & 47.4 & 0.76 & 65.6 & 4.82 & 0.78 & 42.2 & 1624.1 & 3.63 & unknown * \\
9 & 0.78 & 42.2 & 0.82 & 84.2 & 6.18 & 0.84 & 69.7 & 2589.7 & 5.79 & unknown * \\
10 & 0.84 & 70.3 & 0.91 & 271.6 & 19.93 & 0.99 & 3.2 & 14578.9 & 32.57 & unknown * \\
\hline
\end{tabular}

concentration of the compounds can be determined. The bands of separated compounds can be seen (Fig. 4) on the TLC plates visualized under white light and UV of wavelengths $254 \mathrm{~nm}$ and $366 \mathrm{~nm}$.

It has been reported from the previous studies that a wide range of bioactive compounds of medicinal significance are present in various species of Fumaria. The HPTLC study conducted on Fumaria vaillantii showed the presence of protopine and rutin in methanol extract of the whole plant at Rf 0.51 and 0.26 , respectively [11]. Some of the Fumaria species are known to exhibit antifungal [12], antibacterial [13], and anti-inflammatory [14] activities due to the presence of bioactive phytochemicals such as alkaloids, polyphenols, and flavonoids. Thus, from the earlier researches, it is evident that various species of Fumaria contain some bioactive compounds important for pharmaceutical industries.

The findings of the present study are limited to the HPTLC analysis of Fumaria parviflora methanolic extract to estimate the presence of different phytochemicals from the chromatogram peaks and obtain the peak tables; however, the identification of the unknown phytochemicals is not done.

\section{Conclusion}

The present study revealed the presence of several phytochemicals in F. parviflora which might be the cause for its healing properties and thus justifies its usage as a remedy in various ailments. New drug formulations require the isolation and identification of

Table 5 HPTLC peak table of methanolic extract of F. parviflora Lam. (at $366 \mathrm{~nm}$, track 1)

\begin{tabular}{ccccccccccc}
\hline Peak & $\begin{array}{c}\text { Start } \\
\text { Rf }\end{array}$ & $\begin{array}{c}\text { Start } \\
\text { Height }\end{array}$ & $\begin{array}{c}\text { Max } \\
\text { Rf }\end{array}$ & $\begin{array}{c}\text { Max } \\
\text { Height }\end{array}$ & $\begin{array}{c}\text { Max } \\
\%\end{array}$ & $\begin{array}{c}\text { End } \\
\text { Rf }\end{array}$ & $\begin{array}{c}\text { End } \\
\text { Height }\end{array}$ & Area & $\begin{array}{c}\text { Area } \\
\%\end{array}$ & Assigned substance \\
\hline 1 & -0.01 & 3.3 & 0.02 & 190.0 & 11.70 & 0.06 & 70.5 & 5384.8 & 11.83 & unknown * \\
2 & 0.06 & 71.0 & 0.08 & 489.0 & 30.12 & 0.13 & 49.0 & 9923.0 & 21.80 & unknown * \\
3 & 0.16 & 43.7 & 0.17 & 48.6 & 2.99 & 0.20 & 33.1 & 987.9 & 2.17 & unknown * \\
4 & 0.27 & 33.8 & 0.31 & 268.0 & 16.51 & 0.41 & 20.7 & 9536.9 & 20.95 & unknown * \\
5 & 0.53 & 24.8 & 0.59 & 32.9 & 2.02 & 0.60 & 32.4 & 1455.0 & 3.20 & unknown * \\
6 & 0.65 & 35.4 & 0.69 & 58.6 & 3.61 & 0.71 & 51.2 & 1992.6 & 4.38 & unknown * \\
7 & 0.75 & 47.1 & 0.77 & 59.5 & 3.66 & 0.79 & 56.8 & 1382.1 & 3.04 & unknown * \\
8 & 0.81 & 52.4 & 0.86 & 307.8 & 18.96 & 0.90 & 119.7 & 9028.8 & 19.83 & unknown * \\
9 & 0.90 & 120.6 & 0.92 & 169.5 & 10.44 & 0.97 & 0.0 & 5834.2 & 12.82 & unknown * \\
\hline
\end{tabular}


Table 6 HPTLC peak table of methanolic extract of F. parviflora Lam. (at $366 \mathrm{~nm}$, track 2)

\begin{tabular}{ccccccccccc}
\hline \multicolumn{2}{c}{$\begin{array}{c}\text { Peak } \\
\text { Peart }\end{array}$} & $\begin{array}{c}\text { Start } \\
\text { Height }\end{array}$ & $\begin{array}{c}\text { Max } \\
\text { Rf }\end{array}$ & $\begin{array}{c}\text { Max } \\
\text { Height }\end{array}$ & $\begin{array}{c}\text { Max } \\
\%\end{array}$ & $\begin{array}{c}\text { End } \\
\text { Rf }\end{array}$ & $\begin{array}{c}\text { End } \\
\text { Height }\end{array}$ & Area & $\begin{array}{c}\text { Area } \\
\%\end{array}$ & Assigned substance \\
\hline 1 & -0.03 & 4.1 & 0.02 & 230.4 & 6.93 & 0.05 & 142.8 & 7276.0 & 8.67 & unknown * \\
2 & 0.05 & 143.3 & 0.07 & 804.9 & 24.20 & 0.09 & 298.2 & 11006.8 & 13.11 & unknown * \\
3 & 0.09 & 300.6 & 0.10 & 455.1 & 13.68 & 0.13 & 82.6 & 6932.7 & 8.26 & unknown * \\
4 & 0.16 & 81.0 & 0.17 & 82.4 & 2.48 & 0.20 & 64.4 & 1728.2 & 2.06 & unknown * \\
5 & 0.20 & 64.4 & 0.24 & 79.3 & 2.39 & 0.27 & 66.4 & 3441.3 & 4.10 & unknown * \\
6 & 0.27 & 67.0 & 0.31 & 465.3 & 13.99 & 0.42 & 32.9 & 17611.8 & 20.98 & unknown * \\
7 & 0.50 & 32.6 & 0.59 & 51.0 & 1.53 & 0.60 & 49.7 & 2854.5 & 3.40 & unknown * \\
8 & 0.64 & 53.3 & 0.69 & 111.7 & 3.36 & 0.71 & 85.8 & 3529.3 & 4.20 & unknown * \\
9 & 0.71 & 86.3 & 0.72 & 98.3 & 2.96 & 0.75 & 72.5 & 2395.1 & 2.85 & unknown * \\
10 & 0.75 & 73.2 & 0.77 & 92.8 & 2.79 & 0.78 & 87.1 & 1888.6 & 2.25 & unknown * \\
11 & 0.81 & 80.7 & 0.85 & 523.2 & 15.73 & 0.88 & 192.9 & 12671.9 & 15.09 & unknown * \\
12 & 0.88 & 194.0 & 0.91 & 331.5 & 9.97 & 0.97 & 1.3 & 12611.5 & 15.02 & unknown * \\
\hline
\end{tabular}

important phyto-compounds possessing pharmacological properties. The HPTLC study carried out for F. parviflora chemical profiling will be helpful in the identification of bioactive compounds and markers, by comparing the $\mathrm{Rf}$ values of the compounds with the reference standards.

\section{Abbreviations}

Lam: Lamarck; Rf: Retention factor; HPTLC: High-performance thin layer chromatography; UV: Ultraviolet; D2: Deuterium; Hg: Hydrargyrum (mercury)

\section{Acknowledgements}

The authors are thankful to Vindhya Herbal Testing \& Research Laboratory, Bhopal, Madhya Pradesh, for providing technical facilities and assistance required for this work.

\section{Collection, identification, and authentication of plant}

The plant material was collected in the month of July 2020 and identified taxonomically by Dr. Suman Mishra, Consultant Taxonomist, Xcellventure Institute of Fundamental Research Pvt. Ltd., Bhopal (MP). She is also a botany scientist in MFP-PARC, Barkheda Pathani, Bhopal. The plant was identified and authenticated as Fumaria parviflora Lam. belonging to the family Fumariaceae by its macroscopic, microscopic, and powder microscopic examination.

\section{Authors' contributions}

$A B$ executed the work and prepared the manuscript. PS planned the work and provided proper guidance for the research. AT contributed to the research design and edited the manuscript. All the authors have read and approved the manuscript.

\section{Funding}

No funding was received for this research.

\section{Availability of data and materials}

All data and material are available upon request.

Ethics approval and consent to participate Not applicable.
Consent for publication

Not applicable.

\section{Competing interests}

The authors declare that they have no competing interests.

\section{Author details}

${ }^{1}$ Department of Life Science, Rabindranath Tagore University,

Village-Mendua, Post-Bhojpur, Distt. Raisen, Bhopal, Madhya Pradesh 464993, India. ${ }^{2}$ Madhya Pradesh Council of Science and Technology, Bhopal, Madhya

Pradesh, India.

Received: 23 September 2020 Accepted: 30 November 2020

Published online: 04 January 2021

\section{References}

1. Sisodiya D, Shrivastava P (2018) Antimicrobial activity of Euphorbia thymifolia (L.) and Manilkara hexandra (Roxb.). Int J Curr Adv Res 7(2):9660-9663

2. Latha SP, Kannabiran K (2006) Antimicrobial activity and phytochemicals of Solanum trilobatum Linn. Afr J Biotechnol 5:2402-2404

3. Sisodiya D, Shrivastava P (2018) Phytochemical screening, thin layer chromatography and quantitative estimation of bioactive constituents in aqueous extract of Manilkara hexandra (Roxb.) dubard. Int J Recent Sci Res 9(1):23083-23086

4. Cooper LN, Blais BS (2004) Theory of cortical plasticity. World scientific publishing, Singapore

5. Kumar S, Sharma AK, Kamboj A (2017) Fumaria parviflora Lam. (Fumitory): a traditional herbal medicine with modern evidence. Asian J Pharm Pharmacol 3(6):200-207

6. Anonymous (2004) The ayurvedic pharmacopoeia of India, 1 Ministry of Health and Family Welfare, New Delhi, Government of India, 84-86.

7. Anonymous (2007) Fumaria parviflora Lam. In: Khare CP (ed) Indian medicinal plants. Springer, Heidelberg, p 275

8. Tilburt JC, Kaptchuk TJ (2008) Herbal medicine research and global health: an ethical analysis. Bull World Health Organ 86:594-599

9. Sisodiya D, Shrivastava P (2017) Qualitative and quantitative estimation of bioactive compounds of Euphorbia thymifolia L. Asian J Pharm Edu Res 6(3): 34-43

10. Thin-layer chromatography evaluation. https://www.merckmillipore.com. Accessed 6 Nov 2020 
11. Upadhye AS, Rajopadhye AA (2011) Botanical and phytochemical standardization of Fumaria vaillantii Loisel. Indian J Nat Prod Resour 2(3): 369-374

12. Moghtader M (2013) In vitro antifungal effects of Fumaria vaillantii Loisel. essential oil on Aspergillus flavus. J Yeast Fungal Res 4:21-25

13. Khamtache-Abderrahima S, Lequart-Pillonb M, Gontierb E, Gaillardb I, Pilardb S et al (2016) Isoquinoline alkaloid fractions of Fumaria officinalis: characterization and evaluation of their antioxidant and antibacterial activities. Ind Crops Prod 94:1001-1008

14. Bribi N, Algieri F, Rodriguez-Nogales A, Vezza T, Garrido-Mesa J et al (2016) Intestinal anti-inflammatory effects of total alkaloid extract from Fumaria capreolata in the DNBS model of mice colitis and intestinal epithelial CMT93 cells. Phytomedicine 23:901-913

\section{Publisher's Note}

Springer Nature remains neutral with regard to jurisdictional claims in published maps and institutional affiliations.

\section{Submit your manuscript to a SpringerOpen ${ }^{\circ}$ journal and benefit from:}

- Convenient online submission

- Rigorous peer review

- Open access: articles freely available online

- High visibility within the field

Retaining the copyright to your article 